\title{
Haematological Changes in Retinal Vasculitis
}

\author{
P.de SOUZA RAMALHO $\dagger$, A. HORMIGO $\ddagger$, R. MARTINS, C. SALDANHA $\dagger \dagger$ and J. \\ MARTINS-SILVAS $+\dagger$ \\ Lisbon, Portugal
}

\begin{abstract}
Summary
Two selected cases of retinal vasculitis, apparently of unknown aetiology, are reported; one case without any systemic or laboratory manifestation and the second case with a clinical picture similar to VKH syndrome and immunodepression. Both cases showed abnormal haematological parameters related to blood viscosity in the early and acute phases which could be manipulated by therapy. Reduction or near normalisation of these haemorrheological parameters coincided with clinical and angiographic improvement. The second case with severe immunodepression was found to be retrovirus HIV-2 positive.
\end{abstract}

There is increasing evidence that retinal vasculitis is associated with auto-immunity ${ }^{1,2}$ but the real mechanism of its complications and tissue damage is not yet clear. Circulatory and vascular obstructive pathology is expected and often seen in fluorescein angiography with increased vascular permeability (disc oedema, periphlebitis often associated with macular oedema) ${ }^{3}$. It was decided that investigations should be carried out to recognise risk factors involved in the microcirculatory haemodyinamics in the line with our previous work, knowing that haematological parameters can be involved in vascular occlusive pathology such as in diabetes, ${ }^{4}$ macroglobulinaemia, sickle cell disease, Behçet's disease ${ }^{5}$ and systemic lupus erythematosus. ${ }^{6}$ In two selected cases of retinal vasculitis of unknown aetiology haematological parameters related to blood viscosity were studied repeatedly during the course of complications and treatment.

\section{Materials and Method}

Besides general routine and ophthalmologi- cal investigations including fluorescein angiography, haemoglobin (hemoximeter $\mathrm{OSM}_{2}$-Radiometer Copenhagen), haematocrit (Microcentrifugation $10.000 \mathrm{~g}, 5$ ), red cell filterability index (rigidity), ${ }^{7}$ plasma viscosity, ${ }^{8}$ red cell aggregation index,${ }^{9}$ erythocyte acethilcolinesterase $(\mathrm{AChE}),{ }^{10}$ were studied and compared to normal controls.

\section{Case 1}

A 56-year-old male noticed floaters in his right eye after a minor trauma and later developed severe impairment of vision with vitreous haze (blood). Eighteen months later he complained of floaters in his left eye and had gradual reduction of vision during the course of 3 weeks. The fundus in the right eye was not visible because of vitreous opacities, there was vitreous haemorrhage and the intraocular pressure (IOP) was $22 \mathrm{~mm} \mathrm{Hg}$. Ultrasound echography demonstrated a flat retina in the same side. His vision was light perception in the right eye and $1 / 10$ in the left eye. He had vitreous haze and the IOP was $12 \mathrm{~mm} \mathrm{Hg}$ in the left eye.

Fundus examination and fluorescein angiography of the left eye showed retinal and preretinal haemorrhages, cotton wool spots, vasculitis

From: Departments of Ophthalmology $\dagger$ and Biochemistry $\dagger \dagger-$ University of Lisbon, Department of Neurology $\ddagger$ IPOFG Lisbon, Naval Hospital Lisbon, Portugal

Correspondence to: Professor P.de Souza-Ramalho, Department of Ophthalmology, University of Lisbon, Hospital de Santa Maria, 1600 Lisbon, Portugal. 
(phlebitis), with vascular wall staining, leakage, capillary occlusions, macular and disc oedema (Fig. 1): General clinical and laboratory investigations were normal except $\alpha 2$ globulins, haematocrit $59.4 \%$, haemoglobulin $20.3 \mathrm{~g} / \mathrm{d} 1$, fibrinogen $800 ; 6.65 \times 10^{6} \mathrm{RBCmm}^{3} ; 19000 \mathrm{WBC} / \mathrm{mm}^{3}$, plasma viscosity 1.52 (normal 1.15 to 1.27 ), red cell filterability index 34.5 (normal $13.9 \pm 2.22$ ) and red cell AChE 465 (normal value 179.2 - 284.2 U/min/ $\mathrm{mg} / \mathrm{Hgb}$ ). With steroids and after plasmaphoresis and medication with aspirin and piracetam abnormal haematological parameters could be improved or normalised and maintained for several months. But when the treatment was stopped the haematological picture became worse (Table I). Regression was observed as soon as treatment was resumed. Inflammatory fundus signs also showed regression after the period of one year and during the seven admissions to hospital for assessment and treatment (Fig.2). Intraocular pressure was raised in both eyes ( 36 and $30 \mathrm{~mm} \mathrm{Hg}$ ), but could be controlled on betablocker drops alone.

Visual acuity improved during this period as the vitreous was clearer and haematological parameters improved or normalised: haemoglobin $14.2 \mathrm{~g} /$ $\mathrm{dl}$, haematocrit $47 \%$, fibrinogen 369 , RBC
$5.4 \times 10^{6} / \mathrm{mm}^{3}$, WBC $7.500 / \mathrm{mm}^{3}$, plasma viscosity $1.23 \mathrm{cp}$ at $37^{\circ} \mathrm{C}$, red cell filterability index 10.000 .

\section{Case 2}

A 35-year-old lady developed diplopia, photophobia and bilateral impairment of visual acuity, in the right eye which started 4 years before admission to hospital. She also had short-lived feverish episodes and more recently suffered from confusion.

Visual acuity was $10 / 10$ in the left eye and hand movements in the right eye. There was vitreous haze in the right eye and concentric constriction of visual field.

Ultrasound echography showed no retinal detachment. ERG was disturbed both photopic and scotopic. EOG was within the normal range in the left eye $(180 \%)$ and subnormal in the right eye $(160 \%)$. Both optic discs were pale with oedema. Details of the fundus in the right eye were not visible. Fluorescein angiography of the left eye showed vasculitis with leakage (Figs. 3 and 4). CT scan showed hydrocephalus. General examination was normal. Laboratory evaluation revealed: $2.78 \times 10^{6} \mathrm{RBC} / \mathrm{mm}^{3}, 8.7 \mathrm{~g}$-dl haemoglobin, 2.700 $\mathrm{WBC} / \mathrm{mm}^{3}$, ESR $100 / \mathrm{hr}$, plasma viscosity 1.49 , red
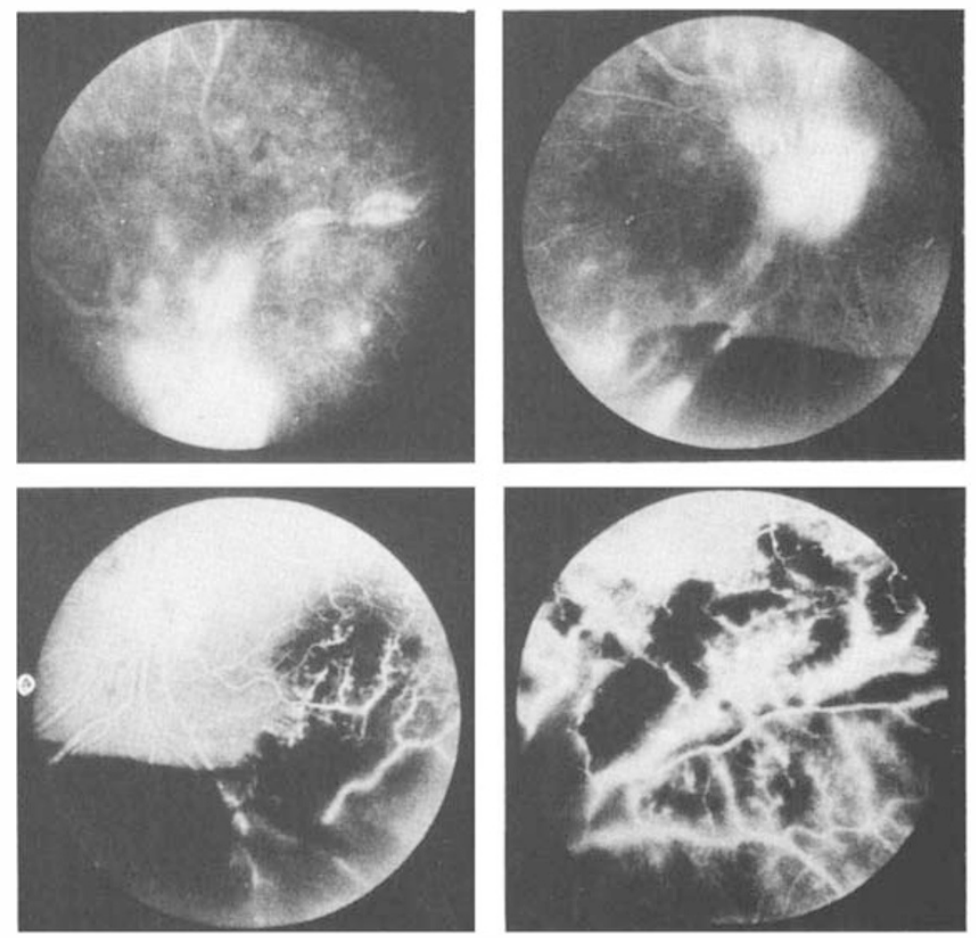

Fig. 1. A composite of 4 photographs of left eye with fluorescein contrast showing leakage staining, vascular occlusions (phlebitis) and haemorrhages. 
cell filterability index $=40.4$. There was an increase in serum IgG and IgM levels; lymphocytic meningeal reaction was present and there was an increase in the intrathecally synthesised $\mathrm{IgG}, \mathrm{IgA}$ and IgM. Negative circulating immune complexes; reduced $\mathrm{C}_{3}, \mathrm{C}_{4}$ and $\mathrm{CH}_{50}$ and $\mathrm{HLA}-\mathrm{A}_{1}, \mathrm{~A}_{2}, \mathrm{~B}_{7}, \mathrm{~B}_{8}$, $\mathrm{DR}_{6}$ and $\mathrm{DR}_{7}$ were demonstrated. Infections and systemic causes responsible for ocular and mening- eal reactions were ruled out. Analysis of T-cells subsets showed OKT $4=10 \%$, OKT $8=40 \%$ with OKT $4 / \mathrm{OKT} 8=0.25 \%$.

Serum antibodies against HIV-1 were negative but they were positive for HIV-2 (ELISA and Western blot method). As she was previously treated with local and systemic corticosteroids with no success, a course of prednisone and chloram-

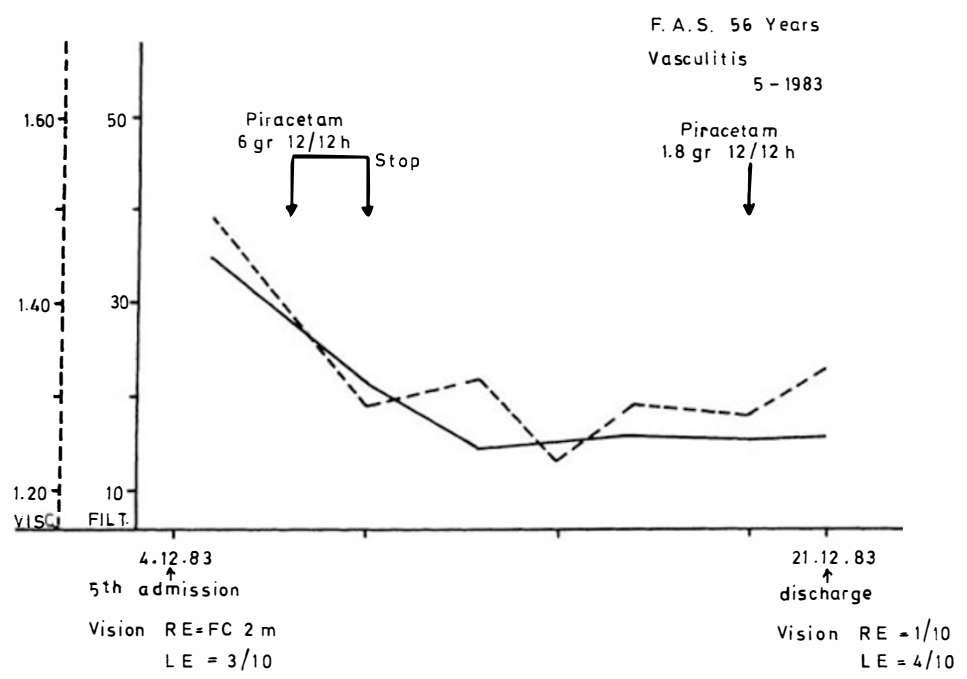

Table I Plasma viscosity and red cell filterability index improvement with treatment during 5 th admission. Note the reduction of blood viscosity parameters a few days after treatment (red cell filterability index, continuous line - FILT; and plasma viscosity dotted line VISC)

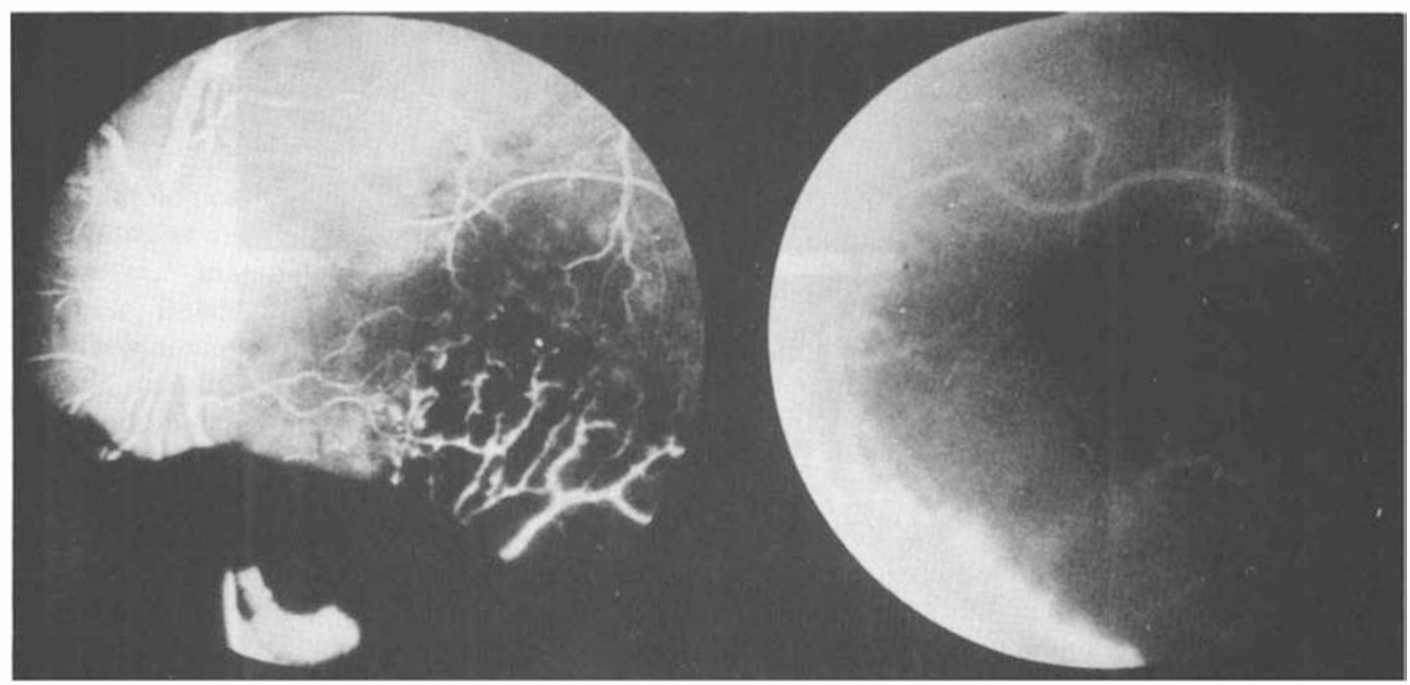

Fig. 2. A composite of 2 fluorescein angiography photographs of left eye showing improvement of fundus picture after treatment and after reducing blood viscosity parameters. Note the difference (left before treatment and right after treatment). The vision in this eye also improved from 1/10 to 4/10. 


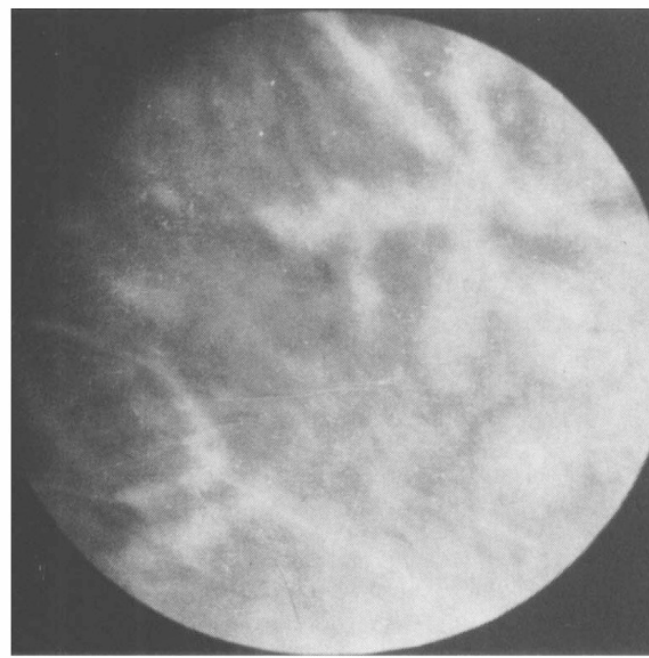

Fig. 3. Fluorescein photograph of the left eye (superior nasal area) showing leakage and staining of the blood vessels (venules).

bucil was tried with clinical and laboratory improvement. Her mental status was normal and she showed less meningeal reaction. Haemoglobin was $9.8 \mathrm{~g} / \mathrm{dl}$, ESR 40/hr, plasma viscosity 1.41 and red cell filterability index 29.2. Her visual acuity also improved to $8 / 10$ in the right eye and the fundus in the same eye was now visible. Fluorescein angiography showed less leakage in both eyes (Figs 4 and 5). Nevertheless there were some defects remaining such as right peripapillary neovascularisation with leakage, pale optic discs and constricted visual field. CT scan showed normal ventricules. With reduction of medication her haematological parameters worsened.

\section{Discussion}

The most striking feature of these 2 cases of retinal vasculitis, one of unknown aetiology probably of auto-immune nature was the presence of abnormal haematological parameters associated with blood viscosity during the initial period when inflammatory signs of phlebitis were observed.

These abnormal haemorheological parameters improved with treatment as also the clinical picture, in both instances. In one case with oculo-neurologic syndrome of Vogt-Koyanagi-Harada type, exhaustive immunological investigations carried out because of immunodepression proved to be

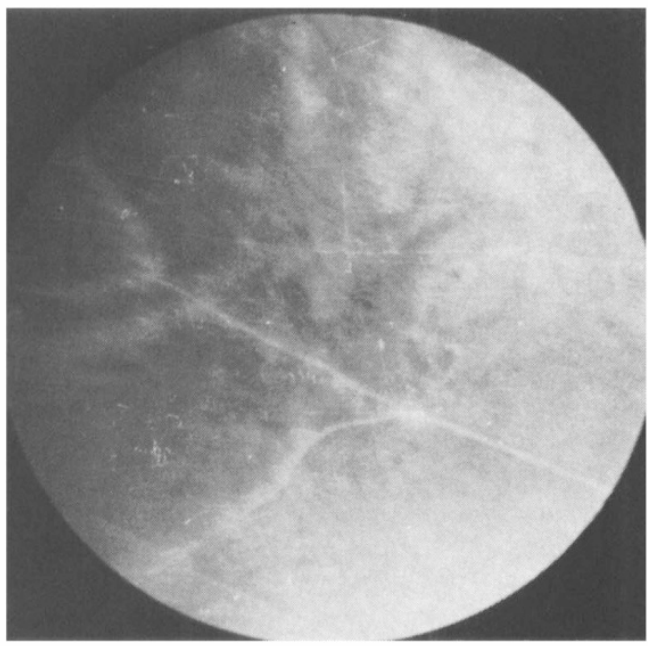

Fig. 4. Fluorescein photograph of the left eye another more peripheral view showing vasculitis with less leakage after treatment.

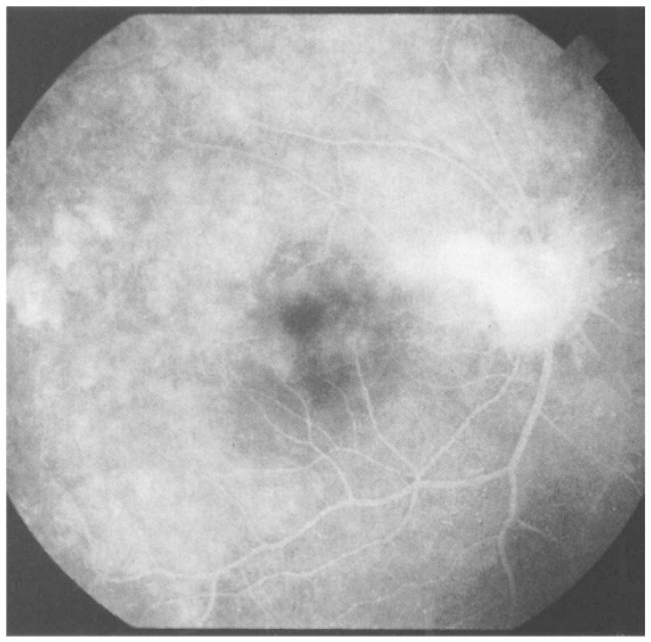

Fig. 5. Fluorescein fundus photograph of the right eye of the same patient as in Figs 3 and 4, now visible after treatment and showing hyperfluorescent disc and leaking parapapillary new vessels (superior temporal). Vision in this eye improved to $8 / 10$.

associated with retrovirus HIV-2, a new finding not yet reported to our knowledge. Similar abnormal haematological parameters were also reported in other clinical vasculitis of SLE and Behçet's disease (6.5). These 
haematological changes, probably of immunologic nature, seen in these cases and suggesting inflammatory activity could well interfere with micro-circulatory haemodynamics thus initiating or aggravating ischaemic complications in small terminal type of blood vessels such as in the retina, SNS and kidneys which could be prevented or alleviated with therapeutic manipulation as in the cases reported.

\section{References}

${ }^{1}$ Dumond DC, Kasp E, Banga JP, et al.: Autoimmune mechanism in inflammatory eye diseases. Trans. Ophthalmol. Soc. UK 1985, 104: 232-8.

2 Stanford MR, Grahm EM, Kasp E, et al.: Retinal vasculitis: Correlation of Animal and Human Disease. Eye 1987. 1: 69-77.

${ }^{3}$ Sanders MD: Retinal vasculitis: a review. $J$. Roy. Soc. Med. 1979, 72: 908-15.

${ }^{4}$ Souza-Ramalho P, Freitas JC, Nunes, et al.: Haemorheology Correlations in Diabetic Retinopathy. Proceedings VII Congress of the
European Society of Ophthalmology. Helsinki 1985, 399-401.

${ }^{5}$ Souza-Ramalho P, Freitas JP, Martins R, et al.: Blood viscosity changes in Behçets disease. In Recent advances in Behçet's disease 1986. Roy Soc. Med. International Congress Series No 103, 159 London, New York.

${ }^{6}$ Souza-Ramalho P. Saldanha C, Jorge P, et al.: Blood viscosity parameters in cotton wool spot retinopathy of SLE. In modern concepts in vitreo-retinal disease 1985 . University of Antwerp, UIA Press. 435-7.

${ }^{7}$ Reid HL, Barnes A, Lock PJ, et al.: Simple method of measuring erythrocyte deformability. J. Clin. Pathol. 1976. 29: 855-8.

${ }^{8}$ Leonard RCF: Simple technique for measuring serum or plasma viscosity with disposable apparatus. Br Med J. 1981. 283: 1154-5.

${ }^{9}$ Schimid-Schoenbein H, Volger E, Teitel P, Kiesewetter H, Heilmann L. New Haemorheological techniques for the routine laboratory. Clin Haemorheol. 1982, 2: 93.

${ }^{10}$ Kaplan E, Herz S, Hsiy KS: Erytrocyte AchE activity in $\mathrm{ABO}$ haemolitic disease of newborn. Pediatrics. 1964, 33: 205. 